\title{
ANALYSIS OF ERROR MOVEMENTS OF MACHINE TOOL SPINDLES
}

\author{
Jarosław CHRZANOWSKI, Tadeusz SAŁACIŃSKI, Tomasz CHMIELEWSKI, Rafał ŚWIERCZ, \\ Krzysztof BIELISZCZUK ${ }^{1}$
}

${ }^{1}$ WUT, Institute of Manufacturing Technology, Warsaw, Poland, EU, krzysztof.bieliszczuk@pw.edu.pl

https://doi.org/10.37904/metal.2021.4144

\begin{abstract}
Condition of a spindle of a machine tool affects not only operation of the machine tool itself, but also, above all, the quality of the machining. This paper short explains the terminology and describes the our own research used to measure the spindle error movements. This article explains the impact of spindle motion inaccuracies on the quality of workpieces and describes the current state and directions of development of the presented methods. Our own program written for research using a commercial kit also presented.
\end{abstract}

Keywords: Spindle error motions, spindle measurement, interpretation of error motions

\section{INTRODUCTION}

Many factors have an influence on process of machining with machine tools (axis parallelism, positioning repeatability, stiffness, precision of measurement system, regulators settings, and others) and they decide about workpiece machining precision and quality. Most of measurement methods used for machine tool precision testing already exist and are developed but practical observations suggest that machine tool spindle state tests are not routine actions in general. Static test (without or with slow spindle rotation) were good enough to determine spindle state of conventional machine tools working and it is obvious that they are not sufficient in case of modern CNC machines equipped with electrospindles.

Range of rotation speeds of contemporary electrospindles is even a few times larger than in conventional machine tools. Even in big industrial facilities there is no equipment for dynamic spindle testing. This is probably a result of the fact that there are few available toolsets dedicated for this purpose, there is no qualified diagnostic staff and cost of equipment and software is in practice a barrier for smaller companies.

Industrial experience shows that spindles - often unfairly - are blamed for problems during workpiece machining. Unfortunately - as described earlier - methods and equipment for spindle error movements tests during work are not widely spread and are known to just a small group of specialists [1-18].

\section{WORKING SPINDLE MOTIONS}

We understand spindle as a sleeve or cylinder rotating around one axis. Axis is usually understood as a point line depicted in machining or assembly technical drawing. In reality spindle is a set of cooperating external and internal surfaces, spherical and other, depending on their design which are manufactured with certain tolerances and shape and location deviations. Each of cooperating cylindrical surfaces has its own axis, but these axes are not the same, they are not even parallel [19].

In reality, during spindle rotation temporary axis of rotation moves creating curved line surfaces wrapped on cylinder or cone and varries from rotation to rotation. Spindle also makes micromoves in radial and axial direction and microrotations around axes perpendicular to main spindle axis. Apart from main axis rotation all other movements are undesirable and called error movements. Global error movement is a superposition of all radial error spindle movements. Its value is the worst possible case which gives an estimation of machine 
tool spindle state. Value of global error movement consists of error movements connected to angular spindle position repeating with every rotation called error synchronous movement as well as error asynchronous movement [20].

Differentiation of those movements is important because their sources are different. Synchronous error movements are connected with spindle rotation speed (spindle angular position). This means that their value is the same every revolution in the same angular position. Asynchronous error movements are not connected to spindle angular position. They are typically "blurred" on pole chart and they influence the quality of machined surface. Despite their sources may be well defined and repetitious they are not synchronized with rotation speed, that is their frequency is not a multiplication of spindle rotation frequency.

\section{SPINDLE ERROR MOTIONS MEASUREMENT SET}

Measurements of spindle motions in machine tool diagnostics described in American standard [21] and on its bases ISO standard of group 230 [22]. Standards present a series of definitions and recommendations but do not describe detailed research methodology especially a way of data collection and analysis. Commercial offer of toolsets dedicated to research of error movements is very poor and sets themselves are rather expensive.

Undesirable micromoves done by spindle have small values usually a few up to - in worst case scenario - a dozen or so micrometers. Reference surface used in machine error movements measurements is a precise (roundness error less than 0.03 micrometer) spherical or cylindrical pattern fixed in tested spindle. In the simplest case error movements in radial and axial directions may be measured with three linear displacement sensors (Figure 1a).

a)

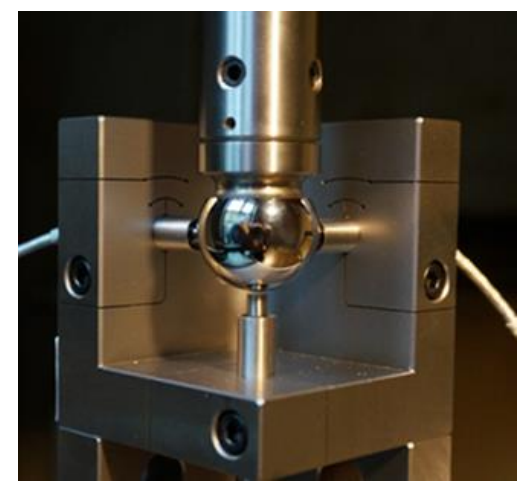

b)

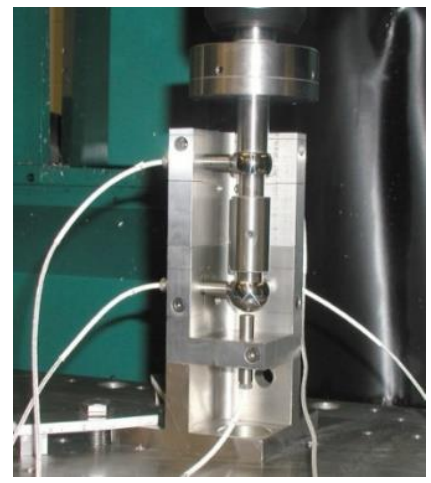

Figure 1 Spindle error move measurement set with a) three gauges; b) five gauges

In special cases [23] when we want to measure error rotations around axes perpendicular to main axis we may for instance use two additional gauges places in plane parallel to XY plane (Figure 1b). Other elements of measurement chain are power supplies and signal amplifiers, DAQ card and computer with software.

\section{SPINDLE TESTS - EXAMPLES}

During conducted research and development work test measurements of error spindle movements were conducted for spindles of machine tools in different technical condition. A commercial set for spindle error movements was used in conjunction with commercial software purchased with equipment as well as self-made software called ABRWS (Analizator Błędnych Ruchów Wrzecion Szybkoobrotowych - in Polish) .

For data acquisition, analysis and result calculation, in this paper work with ABRWS system was described. Program ABRWS is own made software developed for a few years. Basing on own experiences software usage was extremely simplified and measurement process in done automatically. According to authors only few minute training is enough to use the software. Program interface was designed to present only relevant 
information on computer display. Measurement results are displayed on-line on screen and written to file. Program starting screen is presented in Figure 2.

Error movements measurement results for rotating spindle are presented in pole chart showing deviations from spindle rotation axis in subsequent angular positions casted to sensitive direction (radial) and analyzed similarly as chart of roundness deviation for machined workpieces. Chart (left upper corner in Figure 2) presents measurement results collected with 2 sensors $X$ and $Y$ in radial direction. Measurement results in static coordinate system are plotted in background with grey. Determination of error radial movements is based on values of circle radii presenting ideal and real spindle rotary move. Such chart may be subject of further analysis that is to calculate total errors synchronous (correlated with rotation) and asynchronous [20].

Software was written on LabView programming language and uses standard drivers of measurement cards. In menu option named "Configuration" detected measurement card is selected, input channels for the axes sensors are set and (optionally) channel for indexing sensor. In program are included measurements of error movements done without precise pattern [25].

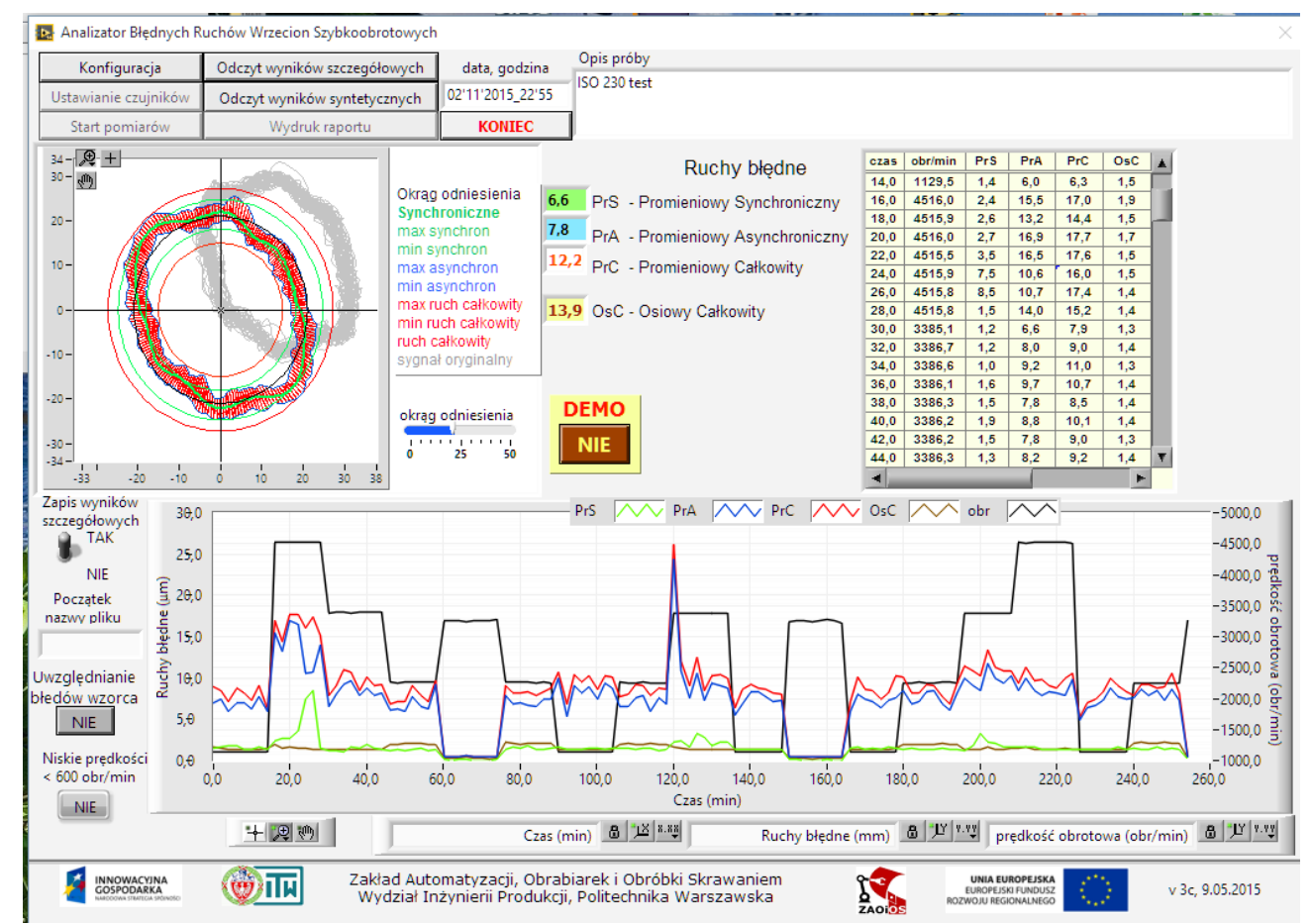

Figure 2 View of ABRWS program starting screen

Bottom chart (Figure 2) automatically generated during measurements at different spindle rotation speeds allows to conclude for instance which speeds should be avoided during machining in which range tightened further measurements, etc.

Program includes procedure for sensor setting that help operator to set sensors properly in relation to spherical pattern. In opposite to commercial software selection of DAQ card parameters is done automatically in background. No knowledge on metrology or signal processing in needed. Program automatically recognizes spindle rotation speed and adjusts sampling frequency. Current test results are displayed on screen under main menu.

Information about spindle state and potential problem causes may be states basing on detailed results (Figure 3). The software has much greater analysis capabilities (for example FFT) and is still being developed. The authors are able to adapt them to the specific needs of the client. For example, you can connect to a database and store data while the state of the spindle changes over time. 


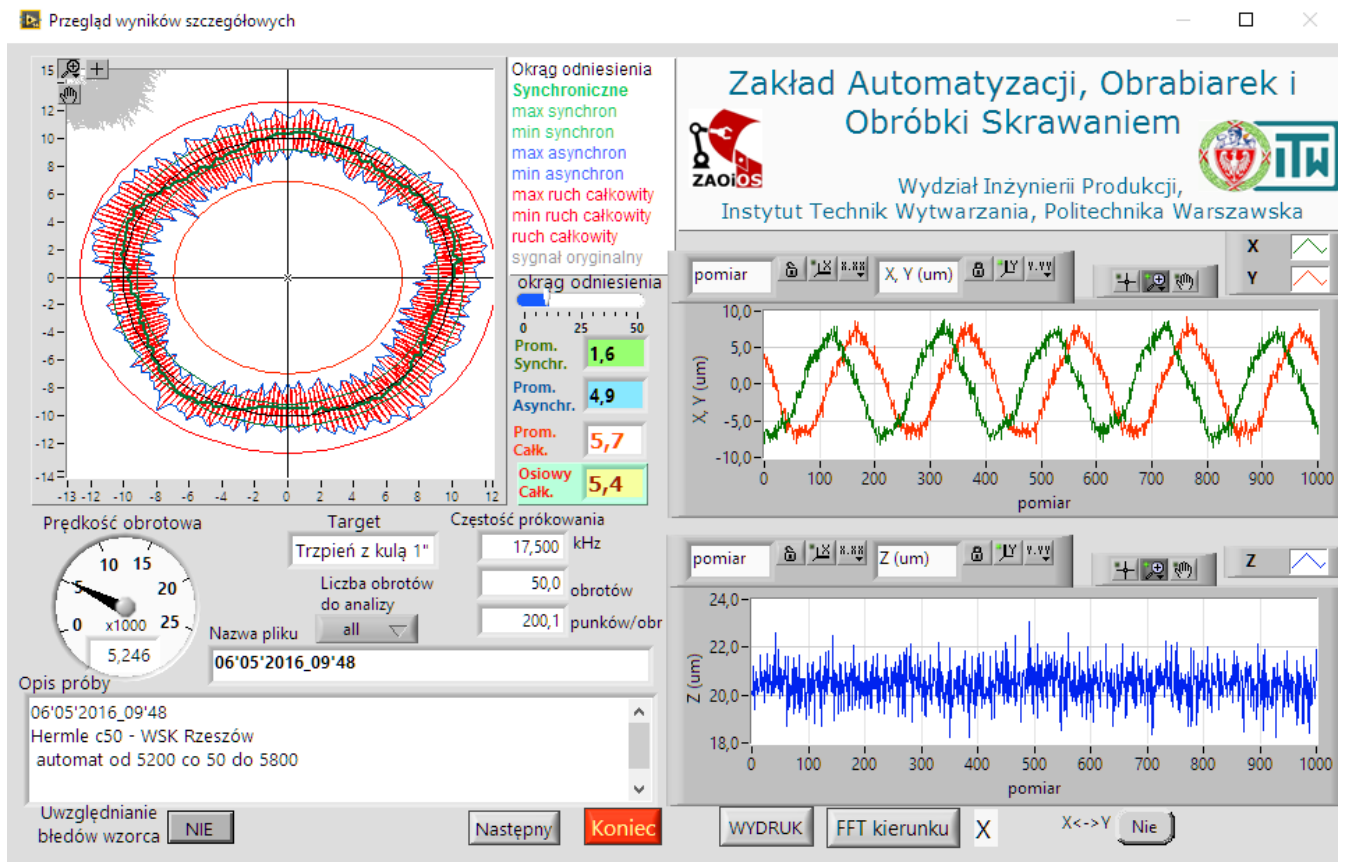

Figure 3 Detailed results screen view (top) for given spindle rotation speed

Presented below examples are connected with tests of a few milling centers in various technical condition. Figure 4 present charts for milling center from 1998 being the property of Institute and working occasionally with speeds $3200 \mathrm{rpm}$ (a1). For comparison: test results for machine tool of the same production year bought from production facility after some years of intense work (b1).

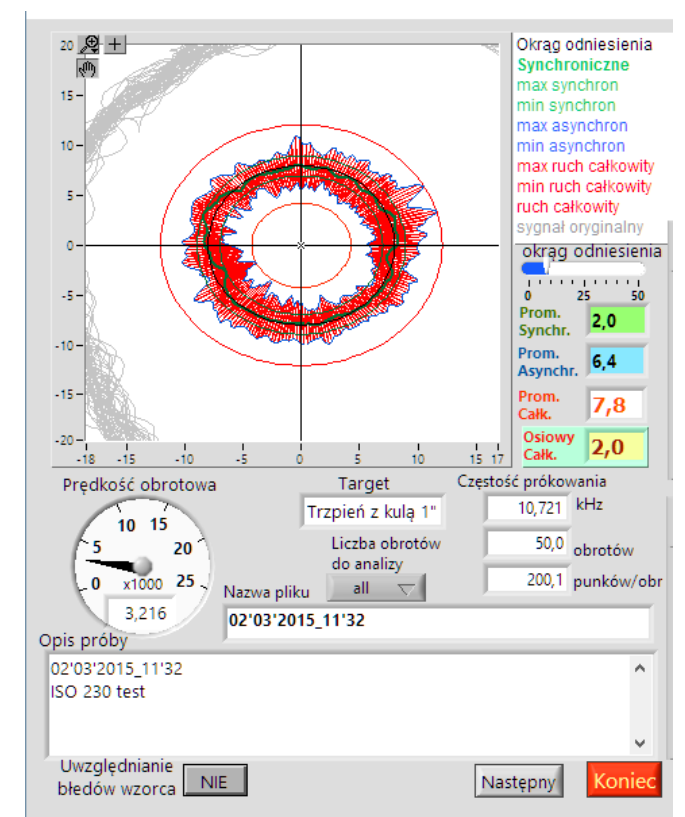

a1)

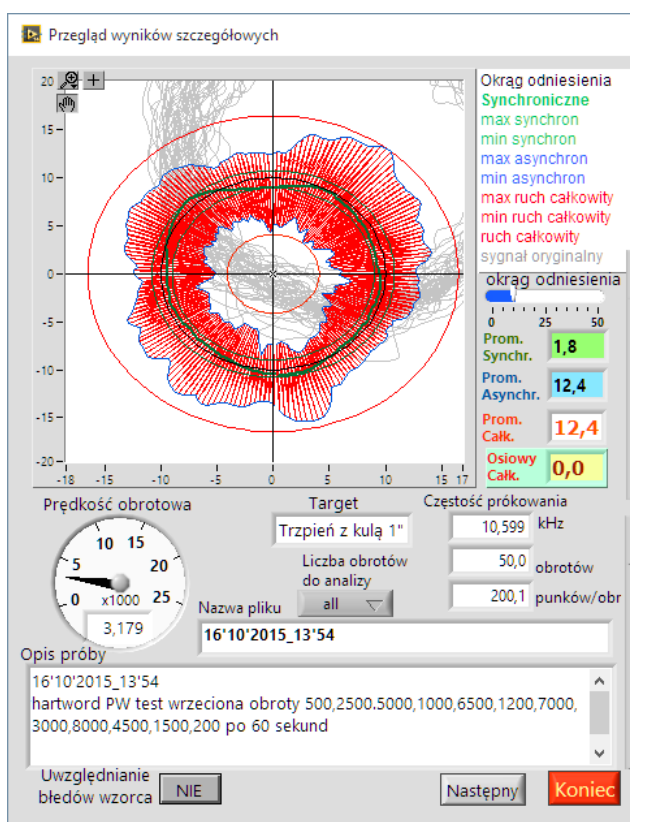

b1)

Figure 4 Pole charts a) machine tool working occasionally, b) working intensively for spindle rotation speed $3200 \mathrm{rpm}$

Interesting results were obtained measuring error movements of spindle speeder mounted in machine tool spindle. Because of cutter diameter limitation fixed in spindle instead of spherical pattern, special cylindrical 
pattern was prepared and used (Figure 5a). Main device of spindle speeder is planetary gear and - as it was easy to predict - synchronous errors dominate with small values of asynchronous errors (Figure $\mathbf{5 b}$ ).
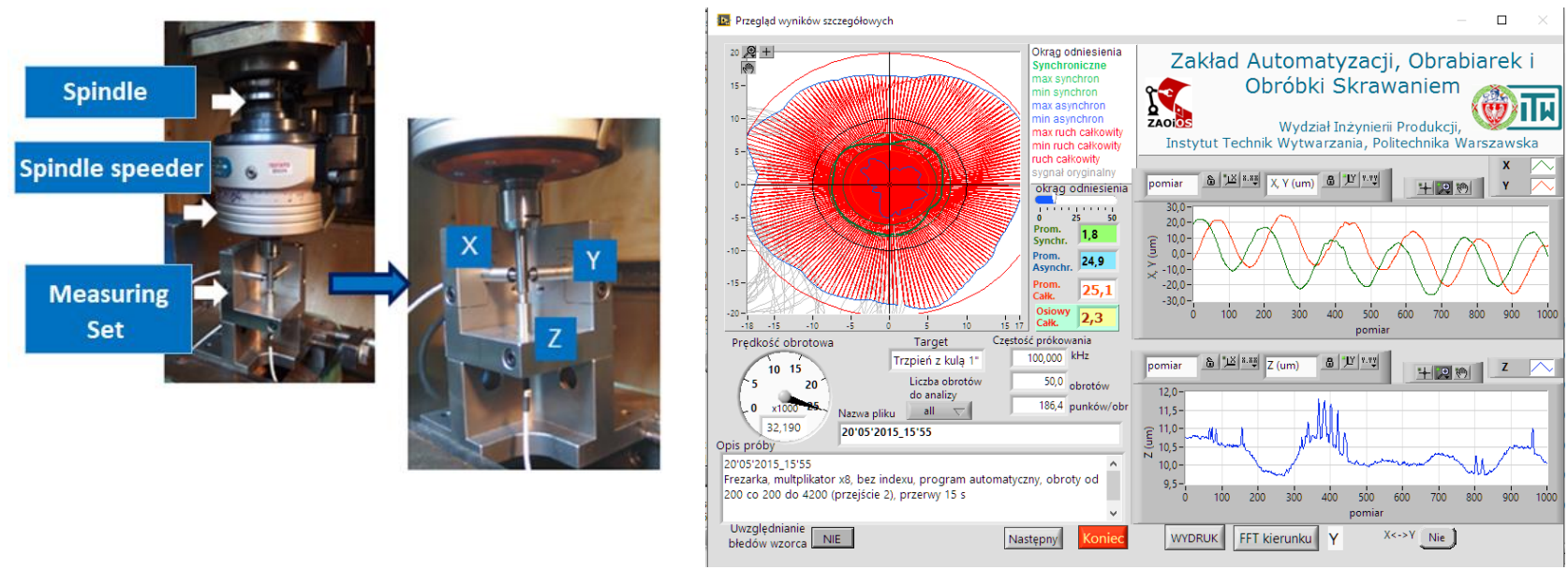

Figure 5 a) Spindle speeder test workstation; b) screen presenting detailed results for revolution spindle speeder - speed 32000 rpm.

Software was tested in industrial measurements. Program is still developed, its capabilities are still widened, for instance with tests for grinding spindles where instead of precise pattern sensors measure imprecise surface of headstock [23]. Software may make measures taking into account temperature changes and its influence on error movements. Option with use of two sphere pattern and 5 sensors was prepared. Program authors are sure of properness of used algorithms and methodology of measurements. Authors are prepared to adjust program even to non-standard users' needs. Program reports may be individually adjusted to needs of ordering company. Cooperation with database in planned in near future.

\section{SUMMARY}

Tests of spindle error movements as one of diagnostic tests for machine tools are not done as standard. In industry only when problems with keeping wanted machining quality appear such tests are wanted. Most maintenance engineers understand that it is more beneficial to prevent malfunctions making diagnostic tests which later remove results of invalid machine tool work. But not everyone knows that there is quick and simple way to diagnose current spindle. There are ready commercial sets dedicated for error movement tests. Available research equipment has very highly and well thought out on design and ergonomics. However commercial software required a lot of knowledge and experience on metrology, data acquisition and data processing. Small number of research centers deals with dynamic spindle tests. Needed specialist knowledge and expensive measurement equipment are source of monopoly of a few companies on worlds market. In practice until now there was no way to compare test results done with commercial set. Pole charts, generated basing on calculations from commercial software, are not proper in opinion of authors of this paper. Nevertheless they may be useful for spindle diagnostics. Change of spindle state will be reflected in values calculated by program.

Own software and algorithms used in it fairly more precisely calculate values of spindle error movements. Software work totally automatically selecting measurement card setting according to real rotation spindle speed. In practice mean educated technical may make measurements on its own.

It should be however emphasized that tests of spindle error movements are done on unloaded machine tool when there are no cutting forces and torques. Test result does not include for example stiffness of machine tool, clearances on slide or axial spindle clearances. 


\section{REFERENCES}

[1] MARSH, E.R. Precision Spindle Metrology. DEStech Publications, Inc.: Lancaster, PA, USA. 2010.

[2] DONALDSON, R. A simple method for separating spindle error from test ball error. CIRP Ann. Manufaturig. Technol. 1972.

[3] ZHANG G., WANG R. Four-Point Method of Roundness and Spindle Error Measurements. CIRP Ann. 1993, vol. 42.

[4] SHI S., LIN J., WANG X., ZHAO M. A hybrid three-probe method for measuring the roundness error and the spindle error. Precis. Eng. 2016, vol. 45.

[5] CHEN Y., ZHAO X., GAO W., HU G., ZHANG S., ZHANG D. A novel multi-probe method for separating spindle radial error from artifact roundness error. Int. J. Adv. Manuf. Technol. 2017, vol. 93.

[6] JIN L., YAN Z., XIE L., GOU W., TANG L. An experimental investigation of spindle rotary error on high-speed machining center. Int. J. Adv. Manuf. Technol. 2013, vol. 70.

[7] CHEN D., FAN J., ZHANG F. An identification method for spindle rotation error of a diamond turning machine based on the wavelet transform from artifact roundness error. Int. J. Adv. Manuf. Technol. 2012, vol. 63.

[8] KIM K., KIM S. Effect of preload on running accuracy of spindle. Int. J. Mach. Tools Manuf. 1989, vol. 29.

[9] HII K.F., VALLANCE R., GREJDA R.D., MARSH E.R. Error motion of a kinematic spindle. Precis. Eng. 2004, vol. 28.

[10] WANG C. A New Laser Non-Contact Method for the Measurement of Spindle Error Motion. Optodyne Inc.: Compton, CA, USA. 2004.

[11] TU J., BOSSMANNS B., HUNG S. Modeling and error analysis for assessing spindle radial error motions. Precis. Eng. 1997, vol. 21.

[12] CASTRO H. A method for evaluating spindle rotation errors of machine tools using a laser interferometer. Measurement. 2008, vol. 41.

[13] GAO W., KIYONO S., SATOH E., SATA T. Precision Measurement of Multi-Degree-of-Freedom Spindle Errors Using Two-dimensional Slope Sensors. CIRP Ann. 2002, vol. 51.

[14] MURAKAMI I. H., KAWAGOISHI N., KONDO E., KODAMA A. Optical Measurement of Five-Degree-of-Freedom Error Motions for a Micro High-Speed Spindle. In: Proceedings of the 4th CIRP International Conference on High Performance Cutting. Gifu, Japan, 24-26 October, 2010.

[15] JYWE W. Y., CHEN C. J. The development of a high-speed spindle measurement system using a laser diode and a quadrants sensor. Int. J. Mach. Tools Manuf. 2005, vol. 45.

[16] LIU C. H., JYWE W. Y., LEE H. W. Development of a simple test device for spindle error measurement using a position sensitive detector. Meas. Sci. Technol. 2004, vol. 15.

[17] SAŁACIŃSKI T., PRZESMYCKI A., CHMIELEWSKI T. Technological Aspects in Manufacturing of Non-Circular Gears. Applied Sciences-Basel. 2020.

[18] PRZESMYCKI A., SAŁACIŃSKI T., WINIARSKI M., CHMIELEWSKI T., ŚWIERCZ R., CIARCIŃSKI D. Influence of ceramic tool processing parameters on the state of NC6 steel surface. In: METAL 2020: 29th International Conference on Metallurgy and Materials. Brno: Tanger, 2020.

[19] CHRZANOWSKI J., JEMIELNIAK K. Pomiary ruchów błędnych wrzecion obrabiarek. Mechanik, Nr $12 / 2015$.

[20] MARSCH E. Precision Spindle Metrology. DEStech Publications. 2008.

[21] B89.3.4 ASME, Axes of Rotation: Methods for Specifying and Testing. 1992.

[22] 230-7 ISO, Test code for machine tools. Part 7: Geometric accuracy of axes of rotation. 2006.

[23] GREJDA R., MARSCH E., RYAN V. Techniques for calibrating spindles with nanometer error motion. Precision Engineering. 2005, no. 29.

[24] CHRZANOWSKI J., JEMIELNIAK K. Spindle error movements measurement algorithm and a new method of results analysis. Journal of Machine Engineering. 2015, no. 1

[25] CHRZANOWSKI J., JEMIELNIAK K. Badania błędnych ruchów wrzecion szlifierek. Mechanik. 2015. no. 8-9. 